\title{
FIXED POINT THEOREMS ON EXPANSION TYPE MAPS IN INTUITIONISTIC FUZZY METRIC SPACE
}

\author{
${ }^{1}$ M.S. Chauhan, ${ }^{2}$ Bijendra Singh , ${ }^{3}$ Bharat Singh, \\ ${ }^{1}$ Nehru govt. P. G. Collage, Agar (Malwa) Dist., Shajapur (M P) India \\ ${ }^{2}$ F-24, Vikram University Campus, Ujjain(M P) India \\ ${ }^{3}$ SOC. and E. IPS. Academy Indore (M P) India \\ *Corresponding address: bharat_singhips@yahoo.com \\ Received 14 September, 2010; Revised 29 April, 2011
}

\begin{abstract}
Ever since the introduction of fuzzy sets by Zadeh [1] , the fuzzyness invaded almost all the branches of crisp mathematics. Deng [3] kaleva and Seikalla [2] and Kramosil and Michalek [5]Have introduced the concept of fuzzy metric space, George and Veeramani [4] modified the concept of fuzzy metric space introduced by kramosil and michalek [5]. In thia paper effort has been made to obtain some results on fixed points of expansion type mapping in Intuitionistic fuzzy metric space
\end{abstract}

\section{INTRODUCTION}

The concept of fuzzy sets was introduced by Zadeh [1] . Following the concept of fuzzy sets, fuzzy metric spaces have been introduced by Kramosil and Michalek [5], George and Veeramani [4] modified the notion of fuzzy metric space with the help of continuous t-norms.

As a generalization of fuzzy sets, Atanassov [21] introduced and studied the concept of intuitionistic fuzzy sets. Using the idea of intuitionistic fuzzy sets Park [16] defined the notion of intuitionistic fuzzy metric space with the help of continuous $t$ norm and continuous $t$ conorm as a generalization of fuzzy metric space, George and Veeramani [4] had showed that every metric induces an intuitionistic fuzzy metric and found a necessary and sufficient condition for an intuitionistic fuzzy metric space to be complete. Choudhary [22] introduced mutually contractive sequence of self maps and proved a fixed point theorem . Kramosil and michalek [5] introduced the notion of Cauchy sequences in an intuitionistic fuzzy metric space and proved the well known fixed point theorem of Banach [10] . Turkoglu et al [20] gave the generalization of Jungek,s common fixed point theorem [24] to intuitionistic fuzzy metric space.

\section{PRELIMINARIES}

Definition 2.1 [7] A binary operation $*:[0,1] \times[0,1] \rightarrow[0,1]$ is called a continuous tnorm if

$([0,1], *)$ is an abelian topological monoid with the unit 1 such that $a * b \leq c * d$ whenever 
$a \leq c$ and $b \leq d$ for all $a_{y} b_{y} c_{y} d \in[0,1]$.

Examples of t-norms are $a * b=a b$ and $a * b=\min \{a, b\}$

* Address of corresponding author

Definition 2.2 [7] A binary operation $0:[0,1] \times[0,1] \rightarrow[0,1]$ is continuous t-conorm if $\diamond$ is satisfying the following condition

2.2.1 0 is commutative and associate

2.2.2 $\diamond$ is continuous

2.2.3 $a \bullet 0=a$ for all $a \in[0,1]$

2.2.4 $a \bullet b \leq c \vee d$ whenever $a \leq c$ and $b \leq d$ for all $a, b, c_{y} d \in[0,1]$

Definition 2.3 [4] the 3-tuple (X, M, $*$ ) is called a fuzzy metric space (FM-space) if $\mathrm{X}$ is an arbitrary set $*$ is a continuous t-norm and $\mathrm{M}$ is a fuzzy set in $X^{2} \times[0, \infty]$ satisfying the following conditions for all $x_{y} y_{s} z \in X$ and $t_{s} s>0$.

2.3.1 $M\left(x_{y}, y, 0\right)>0$

2.3.2 $M(x, y, t)=1, \forall t>0$ iff $x=y$

2.3.3 $M\left(x_{y}, y_{s} t\right)=M\left(y_{x} x_{y}, t\right)_{x}$

2.3.4 $M\left(x_{y} y_{s} t\right) * M\left(y_{s} z_{y} s\right) \leq M\left(x_{y} z_{y} t+s\right)$

2.3.5 $M\left(x_{y} y_{s}.\right):[0, \infty] \rightarrow[0,1]$ is continuous.

Remark 2.1 since $*$ is continuous, it follows from (2.3.4) that the limit of a sequence in FM-space is uniquely determined

Definition 2.4 [16] A five -tuple $\left(X, M, N, *_{x} \diamond\right)$ is said to be an intuitionistic fuzzy metric space if $\mathrm{X}$ is an arbitrary set $*$ is a continuous $\mathrm{t}-$ norm, $\diamond$ is a continuous $\mathrm{t}$-conorm and $\mathrm{M}$, $\mathrm{N}$ are fuzzy sets on $X^{2} \times(0, \infty)$ satisfying the following conditions for all $x_{s} y_{s} z \in X_{s} s, t>0$

2.4.1 $M\left(x_{s} y_{s} t\right)+N\left(x_{y} y_{s} t\right) \leq 1$

2.4.2M(x, $\left.y_{s} t\right)>0$ 
2.4.3 $M\left(x_{y}, y_{3}, t\right)=M\left(y_{3}, x_{2}, t\right)$

2.4.4 $M\left(x_{s} y_{s} t\right) * M\left(y_{s} z_{p} s\right) \leq M\left(x_{y}, z_{p} t+s\right)$

2.4.5 $M\left(x_{3} y_{3 .}\right):(0, \infty) \rightarrow(0,1)$ is continuous

2.4.6 $N\left(x_{y}, y_{s} t\right)>0$

2.4.7 $N\left(x_{s}, y_{,} t\right)=N\left(y_{s}, x_{,} t\right)$

2.4.8 $N\left(x_{s} y_{s} t\right) \bullet N\left(y_{s} z_{s} s\right) \geq N\left(x_{y} z_{s} t+s\right)$

2.4.9 $N\left(x_{z}, y_{3}\right):(0, \infty) \rightarrow(0,1]$ is continuous

Then $(\mathrm{M}, \mathrm{N})$ is called an intuitionistic fuzzy metric on $\mathrm{X}$, the function $M\left(x_{z} y_{s} t\right)$ and $N\left(x_{s} y_{s} t\right)$ denote the degree of nearness and the degree of non- nearness between $\mathrm{x}$ and $\mathrm{y}$ with respect to $t$ respectively

Remark 2.2 Every fuzzy metric space (X, M, *) is an intuitionistic fuzzy metric space form $\left.X_{s} M_{s} 1-M_{s} *_{s} 0\right)$ such that t-norm $*$ and t-conorm $\diamond$ are associated ie $x \vee y=1-((1-x) *(1-y))$ for any $x_{y} y \in[0,1]$ but the converse is not true

Example 2.1 ( induced intuitionistic fuzzy metric space [16] )

Let $(\mathrm{X}, \mathrm{d})$ be a metric space denote $a * b=a b$ and $a, b=\min \{1, a+b\}$ for all $a, b \in[0,1]$ and let $\mathrm{M}$, and $\mathrm{N}$ be fuzzy sets on $X^{2} \times(0,1)$ defined as follows

$M(x, y, t)=\frac{t}{t+d(x y)}$

$N(x, y, t)=\frac{d(x y)}{t+d(x y)}$ then

$\left(X_{y} M_{s} N_{s} * 0\right)$ is an intuitionistic fuzzy metric space. We call this intuitionistic fuzzy metric induced by a metric $d$ the standard intuitionistic fuzzy metric

Remark2.3 note that the above example holds even with the t-norm $a * b=\min \{a, b\}$ and the t-conorm

$a, b=\max \{a, b\}$

Example 2.2 Let $X=N$ define $a * b=\max \{0, a+b-1\}$ and $a, b=a+b-a b$ for all $a, b \in[0,1]$ and let $\mathrm{M}$ and $\mathrm{N}$ be fuzzy sets on $X^{2} \times(0, \infty)$ as follows 


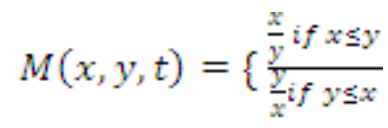

$N(x, y, t)=\left\{\frac{\frac{y-1 x^{i}}{y} x \leq y}{\frac{z-y}{x} \text { if } y \leq x}\right.$

for all $x_{y} y \in X$ and $t>0$ then $\left(X_{y} M_{s} N_{s} *_{p} 0\right)$ is an intuitionistic fuzzy metric space

Remark 2.4 Note that in above example, t-norm $*$ and t- conorm $\diamond$ are not associated, and there exist no metric d on X satisfying $M(x, y, t)=\frac{t}{t+d(x y)}, N(x, y, t)=\frac{d(x y)}{t+d(x y)}$

Where $M\left(x_{y} y_{s} t\right)$ and $N\left(x_{y}, y_{s} t\right)$ are defined in above example, also note that the above functions $(\mathrm{M}, \mathrm{N})$ is not an intuitionistic metric with the t-norm and t-conorm defined as $a * b=\min \{a, b\} a \bullet b=\max \{a, b\}$

Definition 2.5 [16] let $\left(X_{s}, M_{s} N_{s} * 0\right)$ be an intuitionistic fuzzy metric space then

(a)A sequence $\left\{x_{n}\right\}$ in $X$ is said to be convergent $\mathrm{x}$ in $\mathrm{X}$ if for each $\varepsilon>0$ and each $t>0$ there exists $n_{0} \in N$ such that $M\left(x_{n}, x, t\right)>1-\varepsilon$ and $N\left(x_{n}, x_{0}, t\right)<\varepsilon$ for all $n \geq n_{0}$

(b) An intuitionistic fuzzy metric space in which every caucy sequence is convergent is said to be complete

Lemma 2.1 in intuitionistic fuzzy metric space $\mathrm{X}, M\left(x_{y} y_{x}\right)$ is non decreasing and $N\left(x_{y} y_{s}\right)$ is non increasing for all $x_{y} y \in X$

Lemma 2.2 let $\left(X_{p}, M_{p} N_{s} *_{p}, 0\right)$ be an intuitionistic fuzzy metric space if there exist $k \in(0,1)$ such that $M\left(x_{p} y_{3} k t\right) \geq M\left(x_{y} y_{n} t\right)$ and $N\left(x_{p} y_{3} k t\right) \leq N\left(x_{z} y_{s} t\right)$ for all $x_{p} y \in X$ then $x=y$ Proof: since $M\left(x_{y}, k t\right) \geq M\left(x_{s}, y_{s}, t\right)$ and

$N\left(x_{y} y_{s} k t\right) \leq N\left(x_{y} y_{s} t\right)$ then we have

$M\left(x_{p}, y_{s} t\right) \geq M\left(x_{y}, y_{s}, \frac{t}{k}\right)$ and

$N\left(x_{y}, y, t\right) \leq N\left(x_{y}, y_{3} \frac{t}{k}\right)$

By reapeted application of above inequality as we have

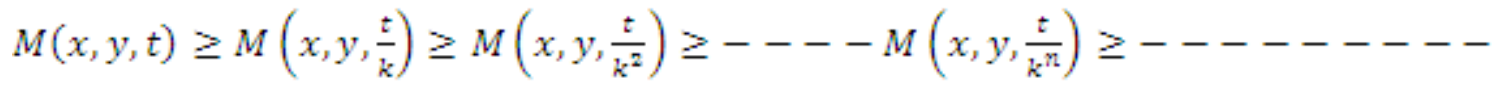

And

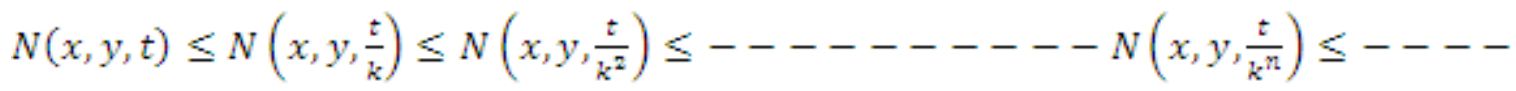

For $n \in N$ which tends to 1 and 0 as $n \rightarrow \infty$ respectively thus

$M\left(x_{y}, y, t\right)=1$ and $N\left(x_{y}, y_{s} t\right)=0$ for all $t>0$ and we get $x=y$ 
Lemma 2.3 let $\left(X_{y} M_{y} N_{s} *_{y},\right)$ be an intuitionistic fuzzy metric space if there exists a number $k \in(0,1)$ such that

$M\left(y_{n+2}, y_{n+1}, q t\right) \geq M\left(y_{n+1}, y_{n}, t\right)$

$N\left(y_{n+2}, y_{n+1}, q t\right) \leq N\left(y_{n+1}, y_{n}, t\right)$ for all $t>0$

And $n=1,2---$ then $\left\{y_{n}\right\}$ is a Cauchy sequence in $\mathrm{X}$

Proof: for $t>0$ and $k \in(0,1)$ we have

$M\left(y_{2}, y_{3}, k t\right) \geq M\left(y_{1}, y_{2}, t\right) \geq M\left(y_{0}, y_{1}, \frac{t}{k}\right)$ or

$M\left(y_{2}, y_{3}, t\right) \geq M\left(y_{0}, y_{1}, \frac{t}{k^{2}}\right)$ and

$N\left(y_{2}, y_{3}, k t\right) \leq N\left(y_{1}, y_{2}, t\right) \leq N\left(y_{0}, y_{1}, \frac{t}{k}\right)$ or

$N\left(y_{2}, y_{3}, t\right) \leq N\left(y_{0}, y_{1}, \frac{t}{k^{2}}\right)$

by simple induction with the condition (1) we have for all $t>0$ and $n=0,1,2,---$ $M\left(y_{n+1}, y_{n+2}, t\right) \geq M\left(y_{1}, y_{2}, \frac{t}{k^{n}}\right)$

$N\left(y_{n+1}, y_{n+2}, t\right) \leq N\left(y_{1}, y_{2}, \frac{t}{k^{n}}\right)$

thus by (2) and (2.4.5) and (2.4.8) for any positive integer $\mathrm{p}$ and real number $t>0$, we have

$M\left(y_{n,} y_{n+p^{p}}, t\right) \geq M\left(y_{n,} y_{n+1} \frac{t}{p}\right) * \ldots$ times ...... $* M\left(y_{n+p-1}, y_{n+p^{p}} \frac{t}{p}\right)$

$N\left(y_{n}, y_{n+p}, t\right) \leq N\left(y_{n,} y_{n+1}, \frac{t}{p}\right) \circ \ldots$ times ....... $0 N\left(y_{n+p-1}, y_{n+p^{p}} \frac{t}{p}\right)$

which $\rightarrow 1$ and $\rightarrow 0$ as $n \rightarrow \infty$ respectively thus $\lim _{n \rightarrow \infty} M\left(y_{n}, y_{n+p^{p}} t\right)=1$ and

$\lim _{n \rightarrow \infty} N\left(y_{n}, y_{n+p^{n}}, t\right)=0$

Which implies that $\left\{y_{n}\right\}$ is a Cauchy sequence in $\mathrm{X}$ this completes the proof

\section{RESULTS}

Theorem 3.1 let $\left(X_{y} M_{y} N_{s} *_{s},\right)$ be a complete IFM-space and $\mathrm{f}$ be a self map of X, onto itself there exist a constant $k>1$ such that

$M\left(f_{x^{\prime}} f_{y^{\prime}} k t\right) \leq M\left(x_{y} y_{s} t\right)$ and

$N\left(f_{x^{\prime}} f_{y^{\prime}} k t\right) \geq N\left(x_{j} y_{y} t\right)$

$f$ or all $x_{y} y \in X$ and $t>0$. Then $\mathrm{f}$ has a unique fixed point in $\mathrm{X}$

Proof: let $x_{0} \in X$ as $\mathrm{f}$ is onto, there is an element $x_{1} \in f^{-1} x_{0}$. In the same way $x_{n} \in f^{-1} x_{n-1}$. For all $n=2,3,4 \ldots \ldots \ldots$ thus we get a sequence $\left\{x_{n}\right\}$, if $x_{m}=x_{m-1}$ for some $\mathrm{m}$ then $x_{m}$ is a fixed point of $\mathrm{f}$ now suppose $x_{n} \neq x_{n-1}$ for all $n=1,2 \ldots \ldots$ then it follows from (1) that 
$M\left(x_{n,}, x_{n+1}, k t\right)=M\left(f_{x_{n+1}}, f_{x_{n+2},} k t\right) \leq M\left(x_{n+1}, x_{n+2}, t\right)$ and

$N\left(x_{n^{\prime}} x_{m+1}, k t\right)=N\left(f_{x_{n+1}{ }^{n}} f_{x_{n+z^{n}}} k t\right) \geq N\left(x_{m+1}, x_{m+2}, t\right)$ for all $t>0$ and for all

$N=0,1,2 \ldots$ therefore by lemma $2.3\left\{x_{n}\right\}$ is a Cauchy sequence in $\mathrm{X}$ since $\mathrm{X}$ is complete $\left\{x_{n}\right\}$ has limit $u \in X$ as $\mathrm{f}$ is onto there is an element $v \in X$ such that $v \in f^{-1} u$. Now

$M\left(x_{n}, u_{y} k t\right)=M\left(f_{x_{n+1}} f_{w}, k t\right) \leq M\left(x_{n+1}, v, t\right)$ and

$N\left(x_{n,}, u_{y} k t\right)=N\left(f_{x_{n+1}} f_{w}, k t\right) \geq N\left(x_{n+1}, v_{s}, t\right)$

which as $n \rightarrow \infty$ gives $M(u, v, t)=1$ and $N(u, v, t)=0$ for all $t>0$, therefore by (IFM

2.4.2) it follows that $u=v$ yielding thereby $f u=u$ and so $\mathrm{u}$ is the fixed point of $\mathrm{f}$. let $\mathrm{u}$ and $\mathrm{v}$ be the two fixed points of $\mathrm{f}$ ie $f u=u$ and $f v=v$ then (1) yields

$M(u, v, k t)=M(f u, f v, t) \leq M(u, v, t)$ and

$N\left(u, v_{s} k t\right)=N(f u, f v, t) \geq N(u, v, t)$ for all $t>0$ hence in view of lemma 2.2 we

obtain $u=v$ which shows the uniqueness of $\mathrm{u}$ as a fixed point of $\mathrm{f}$ this completes the proof

theorem 3.2 let $\left(X_{s} M_{s} N_{s} * 0\right)$ be a complete IFM- space with $t * t \geq t$ and

$(1-t) \bullet(1-t) \leq(1-t)$ for all $t \in[0,1]$ and $\mathrm{f}$ be mapping from $\mathrm{X}$ onto itself there exist a number $k>1$ such that

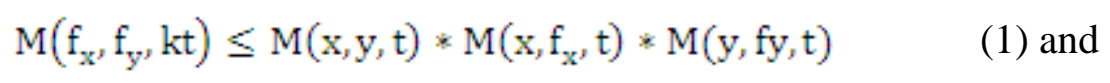

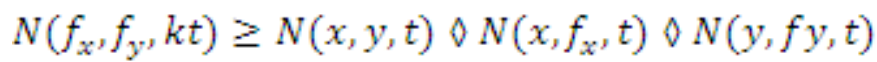

for all $x_{z} y \in X$ and $t>0$ then $\mathrm{f}$ has a unique fixed point in $\mathrm{X}$

Proof : a sequence $\left\{x_{n}\right\}$ is developed similarly as in theorem 3.1, if $x_{m-1}=x_{m}$ for some $\mathrm{m}, \mathrm{f}$ has a fixed point $x_{m}$, suppose $x_{n-1} \neq x_{n}$ for every positive integer $\mathrm{n}$ then from (1)

$$
\begin{aligned}
& M\left(x_{n}, x_{n+1}, k t\right)=M\left(f_{x_{n+1}{ }^{n}} f_{x_{n+2}{ }^{p}} k t\right) \\
& \leq M\left(x_{n+1}, x_{n+2}, t\right) * M\left(x_{n+1}, f_{x_{n+1}}, t\right) * M\left(x_{n+2}, f_{x_{n+2},} t\right) \\
& =M\left(\mathrm{x}_{\mathrm{n}+1}, \mathrm{x}_{\mathrm{n}+2}, \mathrm{t}\right) * \mathrm{M}\left(\mathrm{x}_{\mathrm{n}+1}, \mathrm{x}_{\mathrm{n}}, \mathrm{t}\right) * \mathrm{M}\left(\mathrm{x}_{\mathrm{n}+2}, \mathrm{x}_{\mathrm{n}+1}, \mathrm{t}\right) \text { and } \\
& N\left(x_{n}, x_{n+1}, k t\right)=N\left(f_{x_{n+1}}, f_{x_{n+2}}{ }^{p} k t\right) \\
& \geq N\left(x_{n+1}, x_{n+2}, t\right) \bullet N\left(\mathrm{x}_{\mathrm{n}+1}, \mathrm{f}_{\mathrm{x}_{\mathrm{n}+1}, \mathrm{t}} \mathrm{t}\right) \bullet \mathrm{N}\left(\mathrm{x}_{\mathrm{n}+2}, \mathrm{f}_{\mathrm{x}_{\mathrm{n}+\mathrm{z}^{3}}, \mathrm{t}}\right) \\
& =N\left(\mathrm{x}_{\mathrm{n}+1}, \mathrm{x}_{\mathrm{n}+2}, \mathrm{t}\right) \bullet \mathrm{N}\left(\mathrm{x}_{\mathrm{n}+1}, \mathrm{x}_{\mathrm{n},}, \mathrm{t}\right) \bullet \mathrm{N}\left(\mathrm{x}_{\mathrm{n}+2}, \mathrm{x}_{\mathrm{n}+1}, \mathrm{t}\right)
\end{aligned}
$$

yielding thereby

$$
\begin{aligned}
& M\left(x_{n}, x_{n+1}, k t\right) \leq M\left(x_{n}, x_{n+1}, t\right) * \mathrm{M}\left(\mathrm{x}_{\mathrm{n}+2}, \mathrm{x}_{\mathrm{n}+1}, \mathrm{t}\right) \text { and } \\
& N\left(x_{n}, x_{n+1}, k t\right) \geq N\left(x_{n}, x_{n+1}, \mathrm{t}\right) \bullet N\left(\mathrm{x}_{\mathrm{n}+2}, \mathrm{x}_{\mathrm{n}+1}, \mathrm{t}\right)
\end{aligned}
$$

now suppose

$$
\begin{aligned}
& \mathrm{M}\left(\mathrm{x}_{\mathrm{n}+1}, \mathrm{x}_{\mathrm{n}+2}, \mathrm{t}\right)<M\left(x_{n}, x_{n+1}, \mathrm{t}\right) \text { and } \\
& N\left(x_{n+1}, x_{n+2}, t\right)>N\left(x_{n}, x_{n+1}, t\right)
\end{aligned}
$$


For all $t>0$ then in view of lemma $2.3\left\{x_{n}\right\}$ is a Cauchy sequence in $\mathrm{X}$ which is complete therefore there exists some $u \in X$ such that $x_{n} \rightarrow u$ since $\mathrm{f}$ is onto there is an element $v \in f^{-1} u$ now

$$
\begin{aligned}
& M\left(x_{n_{n}}, u_{x} k t\right)=M\left(f_{x_{n+1}} f_{w^{p}} k t\right) \\
& \leq M\left(x_{m+1}, v_{s} t\right) * M\left(x_{m+1}, x_{n}, t\right) * M\left(v, u_{2} t\right) \text { and } \\
& N\left(x_{n,}, u_{3} k t\right)=N\left(f_{x_{n+1}} f_{v}, k t\right) \\
& \geq N\left(x_{n+1}, v, t\right) \bullet N\left(x_{n+1}, x_{n}, t\right) \vee N\left(v, u_{2}, t\right)
\end{aligned}
$$

Which as letting $n \rightarrow \infty$ gives $M(u, v, t)=1$ for all $t>0$

Therefore by (IFM 2.4.2) it is noting that $u=v$ and sof $u=u$ ie $\mathrm{u}$ is a fixed point of $\mathrm{f}$ the uniqueness of $u$ can be shown easily from (1) hence the theorem proved

Theorem 3.3 let $\left(X_{y}, M_{y} N_{p} * 0\right)$ be a complete IFM- space with $t * t \geq t$ and $(1-t) \bullet(1-t) \leq(1-t)$ for all $t \in[0,1]$ and $f, g$ be two self maps of $X$ onto itself if there exist a number $k>1$ such that

$$
\begin{aligned}
& \mathrm{M}\left(\mathrm{f}_{\mathrm{x}^{\prime}} \mathrm{g}_{\mathrm{y}^{\prime}}, \mathrm{kt}\right) \leq \mathrm{M}\left(\mathrm{x}_{y}, \mathrm{y}_{j} \mathrm{t}\right) * \mathrm{M}\left(\mathrm{x}_{y} \mathrm{f}_{\mathrm{w}^{\prime}} \mathrm{t}\right) * \mathrm{M}\left(\mathrm{y}_{y} \mathrm{~g}_{\mathrm{y}^{\prime}} \mathrm{t}\right) \text { and }
\end{aligned}
$$

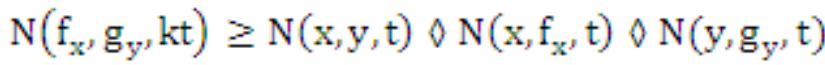

for all $x \in X$ and $t>0$ then $\mathrm{f}$ has a unique common fixed point in $\mathrm{X}$

proof: choose an element $x_{0} \in X$ as $\mathrm{f}$ is onto there is an element $x_{1} \in f^{-1} x_{0}$ since $\mathrm{g}$ is onto there exist an element $x_{2}$ satisfying $x_{2} \in g^{-1} x_{1}$ thus in general a sequence $\left\{x_{n}\right\}$ is defined as $x_{2 n+1} \in f^{-1} x_{2 n}, x_{2 n+2} \in g^{-1} x_{2 n+1}$, for all $n=0,1,2_{y \ldots \ldots} \ldots \ldots$ now we have two cases as follows

case (1) when $x_{m} \neq x_{m+1}$ for all $m=0,1,2 \ldots \ldots$ in this case it follows from (1) that

$$
\begin{aligned}
& M\left(x_{2 n}, x_{2 n+1}, k t\right)=M\left(f_{x_{2 n+1}}, g_{x_{2 n+2},} k t\right) \\
& \leq \mathrm{M}\left(\mathrm{x}_{2 \mathrm{n}+1}, \mathrm{x}_{2 \mathrm{n}+2}, \mathrm{t}\right) * \mathrm{M}\left(\mathrm{x}_{2 \mathrm{n}+1}, \mathrm{x}_{2 \mathrm{n}}, \mathrm{t}\right) * \mathrm{M}\left(\mathrm{x}_{2 \mathrm{n}+1}, \mathrm{x}_{2 \mathrm{n}+2}, \mathrm{t}\right) \\
& \leq \mathrm{M}\left(\mathrm{x}_{2 \mathrm{n}+1}, \mathrm{x}_{2 \mathrm{n}+2}, \mathrm{t}\right) * \mathrm{M}\left(\mathrm{x}_{2 \mathrm{n}}, \mathrm{x}_{2 \mathrm{n}+1}, \mathrm{t}\right) \text { and } \\
& N\left(\mathrm{x}_{2 \mathrm{n}+1}, \mathrm{x}_{2 \mathrm{n}+2}, \mathrm{t}\right)=\mathrm{N}\left(f_{x_{2 n+1},}, g_{x_{2 n+z^{3}}} k t\right) \\
& \geq \mathrm{N}\left(\mathrm{x}_{2 \mathrm{n}+1}, \mathrm{x}_{2 \mathrm{n}+2}, \mathrm{t}\right) \bullet \mathrm{N}\left(\mathrm{x}_{2 \mathrm{n}+1}, \mathrm{x}_{2 \mathrm{n}}, \mathrm{t}\right) \bullet \mathrm{N}\left(\mathrm{x}_{2 \mathrm{n}+1}, \mathrm{x}_{2 \mathrm{n}+2}, \mathrm{t}\right) \\
& \geq \mathrm{N}\left(\mathrm{x}_{2 \mathrm{n}+1}, \mathrm{x}_{2 \mathrm{n}+2}, \mathrm{t}\right) \bullet \mathrm{N}\left(\mathrm{x}_{2 \mathrm{n}}, \mathrm{x}_{2 \mathrm{n}+1}, \mathrm{t}\right)
\end{aligned}
$$

Suppose

$$
\begin{aligned}
& M\left(x_{2 n+1}, x_{2 n+2} k t\right)<M\left(x_{2 n}, x_{2 n+1}, t\right) \text { and } \\
& N\left(x_{2 n+1}, x_{2 n+2} k t\right)>N\left(x_{2 n}, x_{2 n+1}, t\right)
\end{aligned}
$$

then from (2) we obtain

$$
\begin{aligned}
& M\left(x_{2 n}, x_{2 n+1}, k t\right) \leq M\left(x_{2 n}, x_{2 n+1}, t\right) \text { and } \\
& N\left(x_{2 n}, x_{2 n+1}, k t\right) \geq N\left(x_{2 n}, x_{2 n+1}, t\right)
\end{aligned}
$$

Which in view of lemma( 2.2) implies $x_{2 n}=x_{2 n+1}$ which is a contradiction therefore 
Let $\mathrm{M}\left(\mathrm{x}_{2 \mathrm{n}+1}, \mathrm{x}_{2 \mathrm{n}+2}, \mathrm{t}\right) \geq M\left(x_{2 n}, x_{2 \mathrm{n}+1}, t\right)$ and $\mathrm{N}\left(\mathrm{x}_{2 \mathrm{n}+1}, \mathrm{x}_{2 \mathrm{n}+2}, \mathrm{t}\right) \geq N\left(x_{2 n}, x_{2 n+1}, \mathrm{t}\right)$

Then (2) yields

$$
\begin{aligned}
M\left(x_{2 n}, x_{2 n+1}, k t\right) & \leq \mathrm{M}\left(\mathrm{x}_{2 \mathrm{n}+1}, \mathrm{x}_{2 \mathrm{n}+2,} \mathrm{t}\right) \text { and } \\
N\left(x_{2 n}, x_{2 n+1}, k t\right) & \geq \mathrm{N}\left(\mathrm{x}_{2 \mathrm{n}+1}, \mathrm{x}_{2 \mathrm{n}+2^{3}} \mathrm{t}\right)
\end{aligned}
$$

for all $t>0$ similarly it can be shown that

$M\left(x_{2 n+1}, x_{2 n+2} k t\right) \leq M\left(x_{2 n+2}, x_{2 n+1}, t\right)$ and

$N\left(x_{2 n+1}, x_{2 n+2} k t\right) \geq N\left(x_{2 n+2}, x_{2 n+1}, t\right)$

for all $t>0$, thus in general we obtain

$M\left(x_{n,}, x_{n+1}, k t\right) \leq M\left(x_{n+1}, x_{n+2}, t\right)$ and

$N\left(x_{n,}, x_{n+1}, k t\right) \geq N\left(x_{n+1}, x_{n+2}, t\right)$

for all $t>0$ and $n=0,1,2 \ldots \ldots$ hence in view of lemma (2.3) $\left\{x_{n}\right\}$ is a Cauchy sequence in $\mathrm{X}$ which is complete therefore $\left\{x_{n}\right\}$ has a limit point in $\mathrm{x}$ since $\left\{x_{2 n}\right\}$ and $\left\{x_{2 n+1}\right\}$ are subsequence of $\left\{x_{n}\right\}, x_{2 n} \rightarrow u$ and $x_{2 n+1} \rightarrow u$ as $n \rightarrow \infty$ as $\mathrm{f}$ and $\mathrm{g}$ are onto there exist $v, w \in X$ satisfying $v \in f^{-1} u$ and $w \in f^{-1} u$ now

$M\left(x_{2 n}, u_{n} k t\right)=M\left(f_{x_{\mathrm{mM}+1}} g w_{x} k t\right)$

$\leq M\left(x_{2 n+1}, w, t\right) * M\left(x_{2 n+1}, x_{2 n}, t\right) * M\left(w_{s} g w_{s}, t\right)$

And

$N\left(x_{2 n}, u_{s} k t\right)=N\left(f_{x_{2 n+1}}, g w_{s} k t\right)$

$\geq N\left(x_{2 n+1}, w_{n}, t\right) \bullet N\left(x_{2 n+1}, x_{2 n}, t\right) \vee N\left(w_{3} g w_{s}, t\right)$

Which as $n \rightarrow \infty$ gives $M(u, w, t)=1, N(u, w, t)=0$ for all $t>0$ then by (IFM 2.4.2) it follows that $u=w$ in the similar pattern taking $x=v$ and $y=x_{2 n+2}$ in (1) and therefore proceeding as above we obtain $u=v$ therefore $u=v=w$ which immediately implies $f u=g u=u$ and so $\mathrm{u}$ is a common fixed point of $\mathrm{f}$ and $\mathrm{g}$ now let $\mathrm{u}$ and $\mathrm{v}$ be two common fixed point of $\mathrm{f}$ and $\mathrm{g}$ i.e $f u=g u$ and $f v=g v=v$ then

$$
\begin{aligned}
& M(u, v, k t)=M\left(f u, f v_{s} k t\right) \\
& \leq M(u, v, t) * M(u, f u, t) * M\left(v, g v_{s}, t\right) \\
& =M(u, v, t) * 1 * 1=M(u, v, t) \text { and } \\
& N\left(u, v_{s} k t\right)=N\left(f u, f v_{s} k t\right) \\
& \geq N(u, v, t) \bullet N(u, f u, t) \bullet N(u, f u, t) \\
& =N(u, v, t) 0000=N(u, v, t)
\end{aligned}
$$

For all $t>0$ further by application of lemma (2.2) we obtain $u=v$

Case II : when $x_{m-1}=x_{m}$ for some $m$ here $m$ may be even or odd, positive integer without loss of generality suppose $m$ is an integer say $m=2 p$ then $x_{2 p-1}=x_{2 p}$ i.e 
$g_{x_{\mathrm{np}}}=f_{x_{\mathrm{np}-1}}$ which implies $x_{2 p}=x_{2 p+1}$ ( as we have $f x \neq$ fy if $x \neq y$ ) therefore we have $x_{2 p-1}=x_{2 p}=x_{2 p+1}=\cdots$ which shows that $\left\{x_{n}\right\}$ is convergent sequence and so Cauchy sequence in $\mathrm{X}$ the rest of the proof is similar to as in case (I) and this complete the proof

\section{REFERENCES}

[1] Zadeh L A, Fuzzy sets, inform, and control 8 (1965) 338.

[2] Kaleva O, Seikkala, S, On fuzzy metric spaces. Fuzzy sets and system (1962) 122.

[3] Deng Z K, Fuzzy pseudo- metric spaces, J. Math. Anal, Appl. 86 (1982) 74.

[4] George A \& Veeramani P, On some results in fuzzy metric spaces, fuzzy sets and systems 64, (1994) 395.

[5] Kramosil I \& Michalek J, Fuzzy metric and statistical metric spaces kyberntika Appl. 50, (1985)142.

[6] Grabiec M, Fixed points in fuzzy metric spaces, fuzzy sets and systems, 27 (1988) 385

[7] Scweizer B \& Sklar A, statistical metric spaces pacific J Math. 10,(1960) 313.

[8] Rosenholtz, local expansion derivatives and fixed points, Fund. Math 91, (1976)

[9] Rhodes B E , A comparision of various definitions of contractive mappings, trans, Amer. Math, Soc., 57(1976) 257

[10] Banach S Theoric les operations linearires manograie, Mathmatyezne Warsaw, Poland, (1932)

[11] Wang S Z, Li B Y, Gao Z M \& Iseki K, Some fixed point theorems on expansion mappings Math. Japanica, 29, (1984) 631.

[12] Cho Y J, Pathak H K, Kang S M \& Jang J S, Common fixed points of compatible maps of type (b) of fuzzy metric spaces, fuzzy sets and systems 93, (1998) 99. 
[13] Fang $\mathrm{J} X$, On fixed point theorems in fuzzy metric spaces fuzzy sets and systems 46, (1992) 107.

[14] Edelstein M, On fixed and periodic points under contraction mappings , $J$. London Math . Soc. 37, (1962) 74.

[15] Mishra S N, Sharma N \& Singh S I, common fixed point of maps on fuzzy metric spaces, Inter. J. Math. Sci. 17, (1994) 253.

[16] Park J H, Intuitionistic fuzzy metric spaces, Chaos solitons and fractals 22 (2004) 1039

[17] Park J H, Kwun Y C, \& Park J H, A fixed point theorem in the intuitionistic fuzzy metric spaces, far east J. Math. Sci. 16 (2005), 137-149

[18] Saadati R \& Park J H, On the intuitionistic fuzzy topological spaces, chaos, solitons and fractals 27 (2006), 331.

[19] Turkoglu D, Alaca C, Cho Y J \& Yildiz C, common fixed point theorems in intuitionistic fuzzy metric spaces J. Appl, Math, and computing 22(2006), 41.

[20] Turkoglu D, Altun I \& Cho Y J, Common fixed points of compatible mappings of type (I) and type (II) in fuzzy metric spaces, J. fuzzy math. 15(2007), 435.

[21] Atarassov K, Intuitionistic fuzzy set and system 20 (1986), 87.

[22] Choudhary B S, A unique common fixed point theorem for sequence of self maps in menger spaces Bull. Korean math, Soc. 37 (2000). No. 3

[23] Jungck, commuting mappings and fixed points, Amer. Math. Monthly, 83 (1976), 261. 